\title{
Neurodevelopmental Criteria in the Classification of Congenital Motor Nystagmus
}

\author{
J.E. Jan, J.D.A. Carruthers and G. Tillson
}

\begin{abstract}
Congenital motor nystagmus (CMN) can be familial or non-familial. The expressivity of CMN is so variable that in one affected member of the family the oscillations are obvious, while in the others the nystagmus could be overlooked even by the patients themselves. In spontaneous cases the proof of heredity might be discovered by an ophthalmological examination or eye movement recordings of other family members. Our multidisciplinary studies of 27 children with CMN suggests that a neurodevelopmental assessment can also be valuable in establishing a diagnosis of heredity. Our studies suggest that the hereditary form of CMN is free from neurodevelopmental problems, while the non-familial form is not. Therefore, children with spontaneous CMN could be referred for neurodevelopmental evaluation in order to establish a more accurate diagnosis.
\end{abstract}

RÉSUMÉ: Valeur des évaluations neurologiques dans la classification des nystagmus moteurs congénitaux. Le nystagmus moteur congénital (NMC) peut être familial ou non-familial. L'expressivité du NMC est si variable que, chez un membre atteint de la famille les oscillations sont évidentes, alors que chez les autres le nystagmus peut être ignoré des patients eux-mêmes. Dans les cas spontanés, la preuve qu'il s'agit d'une condition héréditaire peut être découverte par un examen ophthalmologique ou un enregistrement des mouvements oculaires chez d'autres membres de la famille. Nos études multidisciplinaires de 27 enfants avec NMC suggèrent qu'une évaluation neurodéveloppementale peut aussi être précieuse pour établir un diagnostic d'hérédité. Nos études suggèrent que, dans la forme héréditaire du nystagmus moteur congénital. il n'y a pas de problème neurodéveloppemental alors que la forme non-familiale n'en est pas exempte. Donc, les enfants avec un NMC spontané pourraient être référés pour évaluation neurodéveloppementale afin d'établir un diagnostic plus précis.

Can.J. Neurol. Sci. 1992; 19: 76-79

Congenital motor nystagmus (CMN) is characterised by binocular, bidirectional, rhythmical, conjugate oscillations of the eyes. The amplitude of the nystagmus is similar in both eyes, the wave form is predominantly horizontal, increases with attempts at fixation and decreases with convergence. The horizontal nature of oscillations persists in upgaze. ${ }^{1-4}$ The onset of nystagmus is at birth, or within a few days afterwards. Anterior visual pathway pathology is absent, or not discernible with present technology. It is sometimes associated with visual loss, but usually the acuity is better than $20 / 80$. Thus occasionally these children might be referred to agencies working with the visually impaired. CMN can be familial or non-familial. The hereditary forms may be autosomal dominant, autosomal recessive, $\mathrm{X}$ linked dominant or X-linked recessive ${ }^{5-6}$ Neither the ophthalmological examination nor the eye movement recording techniques can differentiate between familial and non-familial types of CMN. The hereditary diagnosis is possible only through the identification of more than one affected family member.

Occasionally in children with epilepsy, deafness, microcephaly and other disorders, the neurological evaluation can be quite valuable in differentiating hereditary conditions from dis- orders caused by brain damage. With regard to the visually impaired, it has been shown that over $50 \%$ of children with congenital ocular disorders have additional neurological handicaps but those with inherited eye disorders have significantly fewer disabilities than children who are visually impaired due to asphyxia, infections, injury or tumors. ${ }^{7}$ As a specific example, the dominantly inherited childhood cataracts are not associated with neurological problems while other types, especially rubella cataracts, are. ${ }^{8}$

The purpose of this retrospective study was to see whether the presence or absence of neurodevelopmental problems can be used in differentiating hereditary and non-hereditary forms of CMN in children.

\section{METHODOLOGY}

The Visually Impaired Program, at Children's Hospital evaluates visually impaired children at regular intervals through their childhood and makes appropriate recommendations regarding their habilitation. The assessments involve a paediatric neurologist (JEJ), paediatric ophthalmologists, psychologist, physio-

From the Departments of Paediatrics, Divisions of Neurology (J.E.J.), and Ophthalmology (J.D.A.C., G.T.), University of British Columbia and B.C.'s Children's Hospital, Vancouver

Received February 18, 1991. Accepted in final form September 4, 1991

Reprint requests to: Dr. J.E. Jan, Visually Impaired Program, Children's Hospital, 4480 Oak Street, Vancouver, British Columbia, Canada V6H 3 V4 
therapist, speech and language pathologist, audiologist and other disciplines, depending on the problems. This ambulatory, multidisciplinary process usually takes 1 to 3 days. The operation of the program has been previously described. ${ }^{9}$

The criteria for inclusion in the study were the observation of nystagmus within one week after birth and the absence of anterior visual pathway pathology on one or more examinations by the paediatric ophthalmologist. The nystagmus was binocular, bidirectional, and of similar amplitude in both eyes, predominantly horizontal, increased with attempts at fixation and decreased with convergence. The horizontal nature of oscillations persisted in upgaze. After 1980, almost all children had electroretinograms (ERG) and visually evoked potential studies (VEP) to rule out possible occult retinal disorders.

The distance visual acuity was initially tested binocularly, with the children allowed to hold their heads in the preferential position in order to use the nystagmus null region. Recognition and preferential looking tests were used. Uni-ocular testing was done by fogging their non-fixing eye with a +10.00 lens. Near acuity was also routinely tested. The psychologist selected developmental tests which were suitable for the visually impaired.

In this study, delayed development was diagnosed under the age of 3 to $3 \frac{1}{2}$ years when the child's development was below the expected milestones. Mental retardation was defined as intelligence quotient of 70 or below and was generally diagnosed after 3 to $3^{1 / 2}$ years of age when formal psychological studies could be done. Coordination difficulties were noted during neurological evaluation and learning difficulties by psychological assessment.

\section{RESULTS}

Twenty-seven children with CMN qualified for this study. Sixteen were females. Their birth dates ranged from 1961 to
1988 and the mean age at the last clinic visit was 6.1 years. For analysis these subjects were subdivided according to the presence or absence of neurodevelopmental problems.

Table 1 lists 6 children (22.2\% with no neurodevelopmental difficulties. Five were female. The distance visual acuity in the better eye with correction ranged from $20 / 30$ to 20/80. Patient 1 was seen 17 years ago, her hospital records did not mention any affected family members and she could not be located for a follow-up evaluation. Patients 2-6 had relatives whose diagnosis of CMN was confirmed by ophthalmological assessments except for Patient 2. Her affected uncle lived in another city. In Patient 6 the proof of heredity was reached by obtaining eye movement recordings on the parents and siblings. The child's sister and mother exhibited "micromanifestations of nystagmus" with their eyes closed, but not whilst open, during the recording (Figure 1). The inheritance was thought to be autosomal dominant (3) and autosomal recessive (2) and unknown (1).

\section{Table 1: CMN Without Neurodevelopmental Problems}

\begin{tabular}{ccccccc}
\hline \hline & \multicolumn{5}{c}{$\mathbf{N = 6}$} \\
No. & $\begin{array}{c}\text { Year of } \\
\text { Birth }\end{array}$ & $\begin{array}{c}\text { Vise at } \\
\text { Last Visit in in }\end{array}$ & $\begin{array}{c}\text { Better Eye } \\
\text { Sex }\end{array}$ & $\begin{array}{c}\text { ERG } \\
\text { With Correction VEP }\end{array}$ & Heredity \\
\hline 1 & 61 & 12.5 & $\mathrm{~F}$ & $20 / 60$ & - & - \\
2 & 72 & 11.0 & $\mathrm{~F}$ & $20 / 50$ & $\mathrm{~N}$ & + \\
3 & 79 & 11.0 & $\mathrm{~F}$ & $20 / 30$ & $\mathrm{~N}$ & + \\
4 & 83 & 5.0 & $\mathrm{~F}$ & $20 / 80$ & $\mathrm{~N}$ & + \\
5 & 84 & 5.0 & $\mathrm{~F}$ & $20 / 70$ & $\mathrm{~N}$ & + \\
6 & 88 & 2.5 & $\mathrm{M}$ & $20 / 40$ & $\mathrm{~N}$ & + \\
\hline
\end{tabular}

Legend: $\mathrm{N}=$ Normal; $\mathrm{F}=$ Female; $\mathrm{M}=$ Male

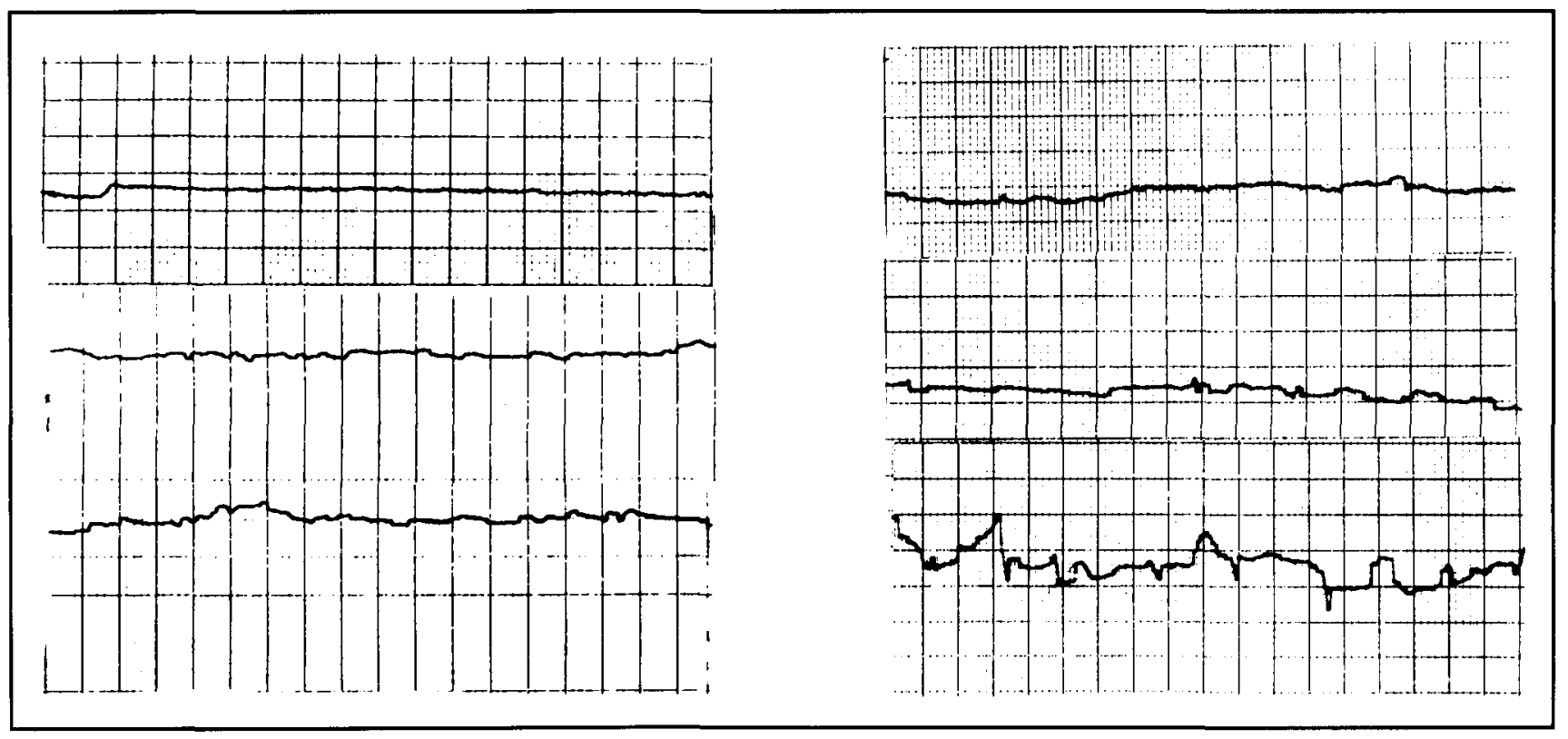

Figure 1 - The eye movement recordings of the mother (right) and the father (left) of a child with spontaneous CMN and no neurodevelopmental problems (Table 1, Patient 6). The recordings were obtained while fixating binocularly at a target (upper line), with eyes looking straight ahead in a completely dark room (middle line) and with eyes closed (bottom line). Note the mother's "micronystagmus" with her eyes closed. She was totally unaware of her disorder. The father's eye movement recordings were normal. The child is now considered to have dominantly inherited CMN. Each square represents $5 \times 5 \mathrm{~mm}$. The paper speed is $25 \mathrm{~mm}$ per second. 
Table 2 shows 21 children (77.8\%) with neurodevelopmental problems. The visual acuity also ranged from $20 / 30$ to $20 / 80$. They had highly variable neurological and neurodevelopmental problems. None of them had a family history of nystagmus. The etiology was unknown in 14 children. In the other seven patients, the presumed etiology was chromosomal defects (3) maternal alcoholism (2), neonatal asphyxia (1) and congenital 4 th ventricle astrocytoma in Patient 15.

ERG and flash VEP studies were done in 15 children and they were always normal. The electroencephalograms of 12 children were reviewed. There were no abnormalities in 8 , nonspecific, generalised dysrhythmia was seen in 3 and the record of one child with epilepsy (Table 2, Patient 4) showed generalised atypical spike and wave discharges. She had idiopathic tonic-clonic seizures. Computed head tomography (CT) was done on 7 children and another child had a pneumoencephalogram. These were normal in all except one child, who had a congenital fourth ventricle astrocytoma (Table 2, Patient 15).

\section{Discussion}

CMN is a neurological disorder which has not, up to now, received much attention in the neurological literature. This is a neurodevelopmental, rather than an ophthalmological study of children who were born with, or developed, CMN within the first week of life and were referred to our program for a multidisciplinary assessment because of their visual impairment or their developmental problems. The vast majority of children with CMN are not visually impaired, therefore this patient population is highly selective.
CMN should not be confused with sensory nystagmus which is associated with severe bilateral congenital ocular lesions. In these children the nystagmus appears weeks or even months after birth and the visual loss is more severe. ${ }^{10}$ Eye movement recordings, however, show similar wave forms to those seen in CMN.

On a clinical basis according to the presence or absence of neurodevelopmental problems we subdivided our patients into two separate groups. The first group had six subjects with CMN and no neurodevelopmental problems. Five of them had similarly affected relatives.

It is well known that the expressivity of CMN is extremely variable. Clinically the oscillations might be quite obvious in one affected member of the family, while in the other it might be so minimal as to be overlooked by physicians, relatives and even by the patients themselves. Shallo-Hoffmann et al." performed electro-oculographic examinations on apparently unaffected family members of 10 patients with "spontaneous" CMN and on a control group of normal volunteers. None of the subjects had evidence of developmental or neurological problems. The eye movement recordings were obtained while fixating binocularly at a target, with eyes looking straight ahead in a completely dark room and also with eyes closed. In contrast, to the control group, fast or slow phase instabilities were observed in $60 \%$ of the families who had a member with spontaneous CMN. The eye movement abnormalities were more frequent in dark and eye closed conditions. The affected individuals were completely unaware of their disorders. The authors concluded that electrooculographic studies can be used to obtain proof of heredity.

Table 2: CMN With Neurodevelopmental Problems

\begin{tabular}{|c|c|c|c|c|c|c|}
\hline No. & $\begin{array}{l}\text { Year of } \\
\text { Birth }\end{array}$ & $\begin{array}{c}\text { Age at } \\
\text { Last Visit }\end{array}$ & Sex & $\begin{array}{c}\qquad \mathbf{N}=21 \\
\text { Vision in Better } \\
\text { Eye With Correction }\end{array}$ & $\begin{array}{l}\text { ERG } \\
\text { VEP }\end{array}$ & Neurodevelopmental Problems \\
\hline 1 & 71 & 2 & $\mathrm{~F}$ & Minimal loss & - & $\mathrm{DD}$ \\
\hline 2 & 71 & 10 & $\mathbf{M}$ & $20 / 70$ & $\longrightarrow$ & LD, language difficulty \\
\hline 3 & 72 & 10 & $\mathrm{~F}$ & $20 / 60$ & - & $\mathrm{CD}, \mathrm{LD}, \mathrm{MR}$ \\
\hline 4 & 76 & 7 & $F$ & $20 / 70$ & - & LD, epilepsy, hyperactive \\
\hline 5 & 78 & 1 & $\mathrm{~F}$ & Minimal loss & 一 & $\mathrm{DD}$ \\
\hline 6 & 80 & 7.5 & M & $20 / 40$ & 一 & $\mathrm{CD}, \mathrm{LD}$, tremor \\
\hline 7 & 82 & 3 & $\mathbf{M}$ & Minimal loss & $\mathbf{N}$ & $\mathrm{DD}, \mathrm{CD}$, hypotonia \\
\hline 8 & 83 & 5.5 & $\mathbf{M}$ & $20 / 80$ & $\mathrm{~N}$ & CD, LD, tremor, hypotonia \\
\hline 9 & 83 & 6.5 & $\mathbf{M}$ & $20 / 40$ & $N$ & $\mathrm{CD}, \mathrm{LD}$ \\
\hline 10 & 83 & 4 & $\mathbf{M}$ & $20 / 50$ & $\mathbf{N}$ & $\begin{array}{l}\text { CD, LD, hypotonia, lordosis, } \\
\text { behavioural difficulties }\end{array}$ \\
\hline 11 & 84 & 5 & $\mathbf{M}$ & $20 / 30$ & $\mathbf{N}$ & $C D$, language difficulty, hyperactive \\
\hline 12 & 86 & 3.5 & $\mathrm{~F}$ & $20 / 30$ & $\mathrm{~N}$ & Tremor \\
\hline 13 & 87 & 2 & $\mathrm{~F}$ & Minimal loss & $\mathbf{N}$ & Language difficulty, hyperactive \\
\hline 14 & 65 & 7 & $F$ & $20 / 30$ & - & MR, CD, microcephaly \\
\hline 15 & 73 & 16 & $\mathbf{M}$ & $20 / 100$ & - & Deaf, ataxia \\
\hline 16 & 75 & 5 & $\mathrm{~F}$ & $20 / 50$ & - & MR, hyperactive, microcephaly \\
\hline 17 & 82 & 3 & $\mathbf{M}$ & Minimal loss & $\mathbf{N}$ & $\mathrm{MR}, \mathrm{CD}$, hypotonic \\
\hline 18 & 84 & 1 & $\mathbf{M}$ & Minimal loss & $\mathrm{N}$ & MR, multiple congenital anomalies \\
\hline 19 & 84 & 4 & $\mathrm{~F}$ & $20 / 100 ?$ & - & Down's syndrome \\
\hline 20 & 84 & 5 & $\mathrm{~F}$ & $20 / 30$ & $\mathrm{~N}$ & CD, LD, tremor, hypotonic \\
\hline 21 & 86 & 2 & $\mathrm{~F}$ & Minimal loss & - & Down's syndrome \\
\hline
\end{tabular}

Legend: $\mathrm{CD}=$ co-ordination difficulties; $\mathrm{MR}=$ mental retardation; $\mathrm{LD}=$ learning difficulties; $\mathrm{DD}=$ delayed development 
The second, larger group contained 21 children with a great variety of neurodevelopmental problems. None of these subjects had a positive family history of nystagmus but the relatives were not assessed. Although the exact lesion in CMN, hereditary or caused by various neurological insults is unknown, the brainstem has been implicated. ${ }^{2}$ However, on the basis of our findings, we were unable to localise the neuropathology to any one area. The neurological, psychological, physiotherapy, speech and language evaluations and EEG studies revealed diffuse, mild to moderate problems without localising features. Even the hand tremor presenting in four children was nonspecific.

In order to offer accurate genetic advice the family members of children with "spontaneous" CMN should always be ophthalmologically assessed. Even minor forms of nystagmus can be discovered by the ophthalmoscope, otherwise, electro-oculographic studies can be performed on the relatives to show micromanifestations of CMN which might not be detected on ophthalmological examinations. Our study suggests that on a clinical basis it might also be possible to divide CMN into familial and non-familial types. Familial $C M N$ is free from neurodevelopmental problems but non-familial CMN is not. Thus, in those children with CMN who have additional neurological problems, the hereditary cause should not be readily accepted without detailed examination of other family members.

Most children with CMN are not visually impaired and do not have neurological or developmental problems. Since our patient population was highly selective and our research was retrospective, it would be important to study without bias a large number of individuals with $\mathrm{CMN}$ and their families. The subjects should have ophthalmological, neurological, developmental assessment and appropriate eye movement recordings.

\section{REFERENCES}

1. Dell'Osso LF, Daroff RB. Congenital nystagmus waveform and foveation strategy. Doc Ophthalmol 1975; 19: 155-182.

2. Yee RD, Wong EK, Baloh RW, et al. A study of congenital nystagmus. Neurology 1976; 26: 326-333.

3. van Vliet AGM. Nystagmus. Doc Ophthalmol 1982; 52: 435-446.

4. Abadi RV, Dickenson CM. Waveform characteristics in congenital nystagmus. Doc Ophthalmol 1986; 64: 153-167.

5. Harcourt B. Hereditary nystagmus in early childhood. J Med Genet 1970; 7: 253-256.

6. Schneiderman LJ, Bartnof HS, Worthen DM. X-linked congenital nystagmus: a problem in genetic counselling. Ann Ophthalmol 1976; 8: 444-446.

7. Robinson GC, Jan JE, Kinnis C. Congenital ocular blindness in children, 1945-1984. Am J Dis Child 1987; 141: 1321-1324.

8. Pike MG, Jan JE, Wong PKH. Neurological and developmental findings in children with cataracts. Am J Dis Child 1989; 143: 706-710.

9. Jan JE, Robinson GC. A multidisciplinary program for visually impaired children and youths. Int Ophthalmol Clin 1989; 29: 3336.

10. Jan JE, Farrell K, Wong PK, et al. Eye and head movements of visually impaired children. Dev Med Child Neurol 1986; 28 : 285-293.

11. Shallo-Hoffmann J, Watermeier D, Petersen J, et al. Electro-oculographic detection of microsymptoms: inherited versus spontaneous cases of congenital nystagmus. Am Orthoptic J 1989; 39: $125-133$.

12. Dell'Osso LF, Daroff RB, Troost BT. Nystagmus and saccadic intrusions and oscillations. In: Duane TD and Jaeger EA, eds. Clinical Ophthalmology. JB Lipincott, Philadelphia. 1988; 2: 1-29. 